\title{
Report of the Korean Association of External Quality Assessment Service on Peripheral Blood Smear Testing for Malaria in 2020
}

\author{
Jeonghyun Chang ${ }^{1 \oplus}$, Hye Ryun Lee ${ }^{2 \oplus}$, Je Eun Song ${ }^{3 \oplus}$, Tae-Hyun Um ${ }^{1 \oplus}$, and Sollip Kim ${ }^{1 \oplus}$ \\ ${ }^{1}$ Department of Laboratory Medicine, Inje University Ilsan Paik Hospital, Goyang; 2Department of Laboratory Medicine, National \\ Medical Center, Seoul; ${ }^{3}$ Department of Internal Medicine, Inje University Ilsan Paik Hospital, Goyang, Korea
}

\section{Corresponding author:}

Sollip Kim

Department of Laboratory Medicine, Inje University Ilsan Paik Hospital, 170 Juhwa-ro, Ilsanseo-gu, Goyang 10380, Korea

Tel +82-31-910-9536

E-mail sollip.kim@paik.ac.kr

This is an Open Access article distributed under the terms of the Creative Commons Attribution Non-Commercial License (http://creativecommons.org/licenses/ by-nc/4.0) which permits unrestricted non-commercial use, distribution, and reproduction in any medium, provided the original work is properly cited.
External quality assessment (EQA) of peripheral blood smear test for malaria was conducted as a pilot project in 2020 by the Korean Association of EQA Service. Two trials were performed with three different cases per trial. Scanned images for the whole slide with brief patient histories were distributed to the participating laboratories online. In total, 208 and 232 laboratories participated in the two trials, respectively. The acceptable rates for malaria detection were $96.1 \%-100.0 \%$ and those for identifying malarial species were $68.1 \%-97.6 \%$. The acceptable rates for parasitemia count were $87.2 \%-94.6 \%$. The EQA scheme assessing peripheral blood smear test for malaria can contribute to the improvement of the diagnostic ability of the participating laboratories.

(Lab Med Qual Assur 2021;43:185-9)

Key Words Korean Association of External Quality Assessment Service, Malaria, Plasmodium, Laboratory proficiency testing

\section{서론}

우리나라는 삼일열 말라리아 토착 국가다. 오래 전부터 유행하 던 말라리아는 국가적 퇴치사업으로 1960년대부터 1984년까지 급속히 줄었지만, 북한과 접해 있는 비무장지대에서 1993년 재출 현한 이후 환자 수는 2015년 말까지 해마다 증가했다[1]. 현재도 1 년에 500 건 전후로 환자 감염이 발생한다. 약 $90 \%$ 가량이 서울, 경기, 그리고 인천지역에서 발생하여 지역 편차가 큰 편이다[2]. 말라리아는 말라리아 원충에 감염된 모기가 사람에게 옮기는 질환 으로, 모기가 주로 생활하는 5월에서 10 월 사이에 발생이 집중되 어 전체 발생의 약 $96 \%$ 를 차지한다[3]. 발병 후 5 일 이내에 빠르 게 치료를 시작하는 것이 중요하여 신속진단검사를 우선적으로 실 시하고 여기에서 양성이 나오면 확진을 위해서 혈액도말을 이용한 말라리아 현미경검경 또는 유전자검사를 시행한다[3]. 신속진단검 사가 음성이더라도 임상적으로 말라리아가 의심되는 경우는 혈액 도말검경 혹은 유전자검출검사를 한다[3]. 또한 치료약제 투여 후
에도 치료효과 판정을 위해 혈액도말검경으로 혈중 원충 정량을 지속적으로 확인해야 한다[3]. 따라서 말라리아 감염의 진단과 치 료과정에서 가장 중요한 검사인 말라리아 혈액도말검경이 검사실 에서 신뢰도 있게 시행되고 있는지 확인하는 것이 중요하기 때문 에, 정확도 확인을 위해서 외부정도관리가 필요하다.

미국, 영국, 에티오피아, 콩고, 말레이시아, 중국 등 여러 말라리 아 발생국가에서 외부정도관리사업을 실시하고 있다[4-9]. 대한임 상검사정도관리협회(Korean Association of External Quality Assessment Service, KEQAS)에서는 2020년에 시범사업으로 혈액도말을 이용한 말라리아 검사를 시작하였다. 시범사업의 프 로그램 개발은 2016년에 발행된 세계보건기구(World Health Organization, $\mathrm{WHO}$ ) 말라리아 검경 품질관리지침을 참고로 하 였다[9]. 저자들은 2020년에 시행한 말라리아 도말검사 외부정도 관리의 과정과 결과를 보고하고자 한다. 


\section{재료 및 방법}

\section{1. 조사항목}

2020년 4월 및 10월에 연 2회에 걸쳐 외부정도관리를 시행하 였다. 회차별로 3 개의 슬라이드 스캔 이미지를 배포하였으며, 말 라리아 검출, 말라리아 종 감별, 말라리아 원충 정량의 세 가지 조 사항목에 대하여 답안을 제출하도록 하였다.

\section{2. 혈액도말 슬라이드 및 스캔 이미지 제조}

외부정도관리에 사용된 혈액도말 슬라이드는 EDTA (ethylenediaminetetraacetic acid) 전혈을 이용하여 인제대학교 일 산백병원 및 국립중앙의료원에서 제조하였다. 일산백병원의 슬라 이드는 SP-10 (Sysmex, Kobe, Japan) 자동화장비를 이용하여 Wright-Giemsa 염색을 시행했다. 국립중앙의료원에서는 수작업 으로 Wright-Giemsa 염색을 시행했다. 1차와 2차 총 6장의 슬라 이드 이미지에 HSM-20-01, HSM-20-02, HSM-20-03, HSM-2004, HSM-20-05, HSM-20-06으로 검체 번호를 부여하였다. 슬 라이드는 PANNORAMIC Digital Slide Scanner (3DHISTECH Ltd., Budapest, Hungary)로 슬라이드의 약 1/3 정도를 400배 배율에서 스캔하였다. 사용자가 모니터로 이미지를 확인할 때 디 지털확대 기능으로 1,600 배까지 배율을 조절하며 판독할 수 있다.

\section{3. 슬라이드 이미지 업로드}

슬라이드 이미지와 해당 슬라이드의 환자 정보를 KEQAS 외부 정도관리 홈페이지(http://eqas.keqas.org)에 연결된 웹사이트 에 외부정도관리 기간에 업로드하였다. 실제 임상상황과 비슷하도 록 환자의 나이, 성별과 거주지역, 여행력, 증상과 함께 일반혈액 검사(complete blood cell count) 결과를 제공하였다.

\section{4. 결과 입력}

참여기관에서는 $\mathrm{KEQAS}$ 외부정도관리 홈페이지에 접속하여 스 캔 이미지를 온라인에서 판독하고, 그 결과를 KEQAS 외부정도관 리 홈페이지에 입력하였다. 말라리아 검출 문항은 양성 또는 음성 으로 응답하도록 하였다. 말라리아 종 감별 문항은 Plasmodium falciparum (P1), P. malariae (P2), P. ovale (P3), P. vivax (P4), unable to identify the Plasmodium species (P5) 중 하 나로 답하도록 하였으며, 말라리아 검출에서 결과를 음성으로 답 하는 경우에는 “말라리아가 관찰되지 않음"을 선택하도록 하였다. 말라리아 원충 정량 문항에는 원충 정량결과를 $\mu \mathrm{L}$ 단위로 응답하 도록 하였고, 말라리아가 관찰되지 않는 경우에는 0 을 입력하도록 하였다.

\section{5. 결과 판정 및 분석}

말라리아 검출 및 종 감별 문항은 $\mathrm{KEQAS}$ 의 정성검사 판정기준 에 따라 참여기관의 $80 \%$ 이상의 일치를 보이는 결과를 intended response로 판정하였다[10]. 말라리아 원충 정량 문항은 KEQAS 의 정량검사 판정기준에 따라 각 기관에 대해 표준편차지수 (standard deviation index, SDI)를 산정하고 3SDI를 넘는 경우 ‘unacceptable'로 판정하였다[10]. 다만 공통된 이미지를 보고 판독하므로 제조회사나 측정기기별로 그룹을 나누지 않고 참여기 관 전체 결과로 SDI값을 산출하였다.

분석한 결과는 참여기관 전체에 대한 '공통보고서'와 각 기관별 결과에 대한 '기관별 보고서'로 작성하여 제공하였고 홈페이지에 서 직접 조회 및 출력할 수 있도록 하였다.

\section{결과}

\section{1. 외부정도관리 참여기관}

2020년 말라리아 혈액도말 외부정도관리는 1회차에 208기관, 2회차에 232기관이 결과를 회신하였다.

\section{2. 응답기관 결과 분포}

\section{1) 말라리아 검출}

2020년의 1차와 2차에 걸친 총 6 개의 슬라이드 이미지 중 양 성은 5 개, 음성은 1 개였다. 정답률은 $96.1 \%-100.0 \%$ 로 높았다 (Table 1).

\section{2) 말라리아 종 감별}

말라리아 종 감별에서는 검체에 따라 정답률이 다양하게 분포 했다. HSM-20-03의 경우 97.6\%로 정답률이 가장 높았으며, 정 답률이 $68.1 \%$ 로 가장 낮았던 $\mathrm{HSM}-20-06$ 의 경우 29 개 기관이 $P$.

Table 1. Proficiency test results for malaria detection in the 2020 report of the Korean Association of External Quality Assessment Service

\begin{tabular}{cccll}
\hline Trial & Cases & Total & $\begin{array}{l}\text { Intended } \\
\text { response }\end{array}$ & Acceptable (\%) \\
\hline \multirow{2}{*}{ 1st } & HSM-20-01 & 208 & Positive & $206(99.0)$ \\
& HSM-20-02 & 208 & Negative & $204(98.1)$ \\
& HSM-20-03 & 208 & Positive & $208(100.0)$ \\
\multirow{2}{*}{ 2nd } & HSM-20-04 & 232 & Positive & $223(96.1)$ \\
& HSM-20-05 & 232 & Positive & $232(100.0)$ \\
& HSM-20-06 & 232 & Positive & $223(96.1)$ \\
\hline
\end{tabular}


Table 2. Proficiency test results for identification of malarial species in the 2020 report of the Korean Association of External Quality Assessment Service

\begin{tabular}{cccccccccc}
\hline Trial & Cases & Total & $\begin{array}{c}\text { P1 } \\
\text { (Plasmodium } \\
\text { falciparum) }\end{array}$ & $\begin{array}{c}\text { P2 } \\
\text { (Plasmodium } \\
\text { malariae) }\end{array}$ & $\begin{array}{c}\text { P3 } \\
\text { (Plasmodium } \\
\text { ovale) }\end{array}$ & $\begin{array}{c}\text { P4 } \\
\text { (Plasmodium } \\
\text { vivax) }\end{array}$ & $\begin{array}{c}\text { P5 (Unable to } \\
\text { identify the } \\
\text { Plasmodium } \\
\text { species) }\end{array}$ & $\begin{array}{c}\text { Acceptable } \\
\text { (\%) }\end{array}$ & $\begin{array}{c}\text { Intended } \\
\text { response }\end{array}$ \\
\hline \multirow{2}{*}{ 1st } & HSM-20-01 & 165 & 3 & 8 & 3 & 147 & 4 & $147(89.1)$ & P4 \\
& HSM-20-03 & 165 & 161 & 1 & 1 & 0 & 2 & $161(97.6)$ & P1 \\
2nd & HSM-20-04 & 182 & 170 & 1 & 0 & 3 & 2 & $170(93.4)$ & P1 \\
& HSM-20-05 & 182 & 3 & 2 & 1 & 176 & 0 & $176(96.7)$ & P4 \\
& HSM-20-06 & 182 & 0 & 29 & 9 & 124 & 3 & $124(68.1)$ & P4 \\
\hline
\end{tabular}

Table 3. Proficiency test results for quantitative parasitemia count in malaria in the 2020 report of the Korean Association of External Quality Assessment Service

\begin{tabular}{cccccccccc}
\hline Trial & Specimen & $\begin{array}{c}\text { No. of } \\
\text { participants }\end{array}$ & $\begin{array}{c}\text { No. of } \\
\text { outliers }\end{array}$ & Min & Max & Median & Mean \pm SD & CV (\%) $\begin{array}{c}\text { Acceptable } \\
(\%)\end{array}$ \\
\hline \multirow{2}{*}{ 1st } & HSM-20-01 & 187 & 24 & 0 & 99,999 & 37,051 & $37,011.1 \pm 9,634.8$ & 26.0 & $163(87.2)$ \\
& HSM-20-03 & 187 & 13 & 188 & 99,999 & 99,999 & $99,999 \pm 0^{*}$ & 0 & $174(93.0)$ \\
\multirow{2}{*}{ 2nd } & HSM-20-04 & 202 & 12 & 0 & 999,999 & 120,333 & $118,574.7 \pm 68,955.2$ & 58.1 & $190(94.6)$ \\
& HSM-20-05 & 202 & 21 & 10,000 & 999,999 & 10,000 & $9,848.2 \pm 3,149.8$ & 32.0 & $181(90.1)$ \\
& HSM-20-06 & 202 & 24 & 0 & 177,480 & 1,740 & $1,720.2 \pm 935.2$ & 54.4 & $178(88.6)$ \\
\hline
\end{tabular}

Abbreviations: SD, standard deviation; CV, coefficient of variation.

${ }^{*} \mathrm{SD}$ was 0 owing to insufficient input space to enter the value.

malariae (P2)로 보고하였고 9개 기관이 P. ovale (P3), 3 개 기관 은 종 감별불가(P5)로 보고하였다(Table 2).

\section{3) 말라리아 원충 정량}

말라리아 원충 정량검사의 정답률은 $87.2 \%-94.6 \%$ 였다. 1 회차에서 정량값을 입력할 수 있는 자릿수가 다섯 자리였는데, HSM-20-03 슬라이드의 정량값이 다섯 자리를 초과하였기 때문 에 평균값이 99,999로, 표준편차가 0으로 집계되었다. 이와 같은 오류를 방지하기 위해 2회차부터 입력 자릿수를 여섯 자리로 수정 하였다(Table 3).

\section{고찰}

말라리아의 진단과 치료를 위해서 혈액도말 슬라이드 검경이 필수임에도 불구하고 슬라이드 대량 제작의 어려움으로 인하여 지 금까지 외부정도관리를 실시하지 못했다. 최근 디지털이미지 기술 의 발달로 슬라이드를 고해상도로 스캔하는 것이 가능해져서 현미 경을 보는 것과 유사한 수준의 이미지를 컴퓨터 스크린을 통해 볼 수 있게 되었고 이 기능을 활용하여 외부정도관리를 시작하게 되
었다. 첫 시범사업에는 혈액도말 말라리아 검사 외부정도관리에 1 차에 208 개 기관, 2차에 232 개 기관으로 2020년 전체 외부정도 관리 참여기관 1,873 개 중 $11.1 \%-12.4 \%$ 가 참여하였다. 우리나 라의 말라리아 주요 발생지역인 서울과 경기, 인천을 제외한 비호 발 지역에서는 1 년에 한두 건 정도로 아주 낮은 빈도로 말라리아 의심 환자 검체가 검사실에 의뢰되고 말라리아 양성률이 낮기 때 문에 검사실에서 혈액도말검경으로 말라리아를 진단할 때 경험 부 족으로 인한 어려움이 있다. 외부정도관리를 통해 다양한 말라리 아 감염 혈액도말 이미지를 접하게 되면서 추후 말라리아 진단에 큰 도움이 될 것으로 생각한다.

일반적으로 말라리아 감염 확인을 위해서 적혈구 내의 ring form이나 trophozoite를 관찰하기 위해서는 현미경의 배 율을 1,000 배로 하여 검경한다[11]. 이번 시범사업에서는 PANNORAMIC Digital Slide Scanner를 이용하여 ideal zone을 포함한 슬라이드 $1 / 3$ 부분을 400 배로 스캔하였는데, 디지털 확대 를 최대한으로 하는 경우 1,600 배까지 배율을 확대할 수 있다. 디 지털 이미지는 말라리아 감염을 감별하기에는 충분했으나 현미경 수준의 해상도를 얻을 수는 없었다. 향후 oil을 사용하여 1,000 배 에서 스캔할 수 있는 oil scanner가 도입되면 해상도가 더 향상될 
것으로 기대한다.

우리나라에서 출현하는 말라리아 감염증의 대부분의 원인 종 은 P. vivax로, 그 외 다른 형태의 말라리아 종은 거의 관찰하지 못 한다[2]. 해외 지역에 따라 우세 원인 종에도 차이가 있어 아프리 카 지역에서는 P. falciparum이 높은 수준으로 발생하는데, 이는 우리나라에서는 관찰하기 어렵다[2]. 해외유입 말라리아 환자에 서는 P. falciparum, P. malariae, P. ovale가 종종 동정되고, 이 들은 현미경에서 관찰할 때 $P$. vivax와는 차이가 있으나 P. vivax 에 익숙해진 우리나라의 검사자들이 형태학적으로 동정하기에 어 려움이 있을 수 있다. WHO 매뉴얼에서는 혈액도말로 종 감별까 지 할 것을 요구하고 있으나[9], 우리나라에서는 말라리아 감염이 의심될 경우 신속항원검사로 먼저 선별하거나 또는 신속항원검사 와 혈액도말검경을 동시에 실시하는 경우가 많기 때문에 혈액도 말검경으로 종 수준까지 감별해야 하는 부담은 적다. 이번 말라리 아 혈액도말 외부정도관리 시범사업에서는 평소 접하지 못했던 $P$. falciparum을 포함하여 이미지를 제공하였기에 교육적인 목적으 로 유용했다고 할 수 있다. 향후 가능한 다양한 종의 말라리아를 포함시킬 계획이다.

원충 정량방법에 대해서는 통일된 기준이 없고, 현재 통용되는 몇 가지 매뉴얼은 다음과 같다. WHO 매뉴얼에 따르면 후층도말 로 200 개의 백혈구를 셌을 때 100 개 이상의 원충이 보이는 경우 에는 백혈구 200 개당 원충 수로 기록하고, 99 개 이하의 원충이 보 이는 경우 500 개의 백혈구까지 세어 500 개 백혈구당 원충 수로 기록하도록 한다. 박층도말에서는 약 5,000 개의 적혈구 중 감염 된 적혈구 수를 기반으로 혈액 마이크로리터당 원충 수를 계산한 다[12]. 미국 Centers for Disease Control and Prevention에 서는 박층도말에서 500-2,000개의 적혈구를 세고 그 중 감염된 적혈구 비율을 퍼센트로 나타내거나 후층도말로 500 개의 원충 또는 1,000 개의 백혈구를 세어 혈액 마이크로리터 당 원충 수로 나타내도 록 한다[13]. 이를 기반으로 향후 외부정도관리 프로그램 운영시 박 층도말에서 적혈구의 개수 기준을 참여기관들이 동일한 기준으로 계 수할 수 있도록 감염 적혈구가 $10 \%$ 이상인 경우 500 개, $1 \%-10 \%$ 인 경우 1,000 개, 그리고 $1 \%$ 미만인 경우 2,000 개 이상의 적혈구를 세
는 것으로 KEQAS 원충 정량 판독기준을 마련하였다.

대부분의 말라리아 치료약은 non-gametocyte를 제거하는 데에 효과가 있다. 이 경우 gametocyte에 대한 효과는 없으며 gametocyte 유무 여부가 임상경과에서도 영향을 주지 않기 때문 에, 초기 진단보다는 치료 후 추적관리에서 약제효과를 판단하기 위한 목적으로 쓰이는 원충 정량에서 gametocyte는 제외되는 것 이 일반적이다[14]. 그러나 최근 gametocytocidal 약물 또는 기 존 약물과의 조합을 치료에 사용하게 되에 따라 gametocyte 검 출도 중요해졌다[14]. 이번 2020년 외부정도관리 시범사업에서는 원충 정량에서 gametocyte와 non-gametocyte를 구별하지 않 고 입력하도록 하였으나, non-gametocyte와 gametocyte의 임 상적 중요도와 의미가 다르기 때문에 향후 외부정도관리에서는 두 가지를 분리해서 계수하고 입력하도록 할 예정이다.

시범사업으로 처음 시행한 외부정도관리로서 미진했던 부분도 있었다. 말라리아 원충 정량 문항에서 1 회차 때 입력 자릿수를 다 섯 자리로 설정했는데, 검체의 정량값이 다섯 자리를 초과하는 값 이 있어서 최종 평균값이 99,999 로, SD가 0으로 집계되었다. 동 일한 오류를 방지하기 위해서 2회차부터는 입력할 수 있는 자릿수 를 여섯 자리로 수정하였다.

혈액도말 말라리아 외부정도관리는 2020년 시범사업을 성공적 으로 마쳤고 2021년부터 정식사업으로 시행되고 있다. 말라리아 혈액도말 외부정도관리는 각 기관에서 말라리아 혈액도말을 판독 할 때 도움을 주고, 검사의 질 향상에 기여할 수 있을 것으로 기대 된다.

\section{ORCID}

Jeonghyun Chang https://orcid.org/0000-0001-7928-7195 Hye Ryun Lee https://orcid.org/0000-0001-9175-6441 Je Eun Song https://orcid.org/0000-0001-7056-6905 Tae-Hyun Um https://orcid.org/0000-0003-4879-9408 Sollip Kim

\section{REFERENCES}

1. Chai JY. History and current status of malaria in Korea. Infect Chemother 2020;52:441-52.

2. Kan H, Kwon J, Park S, Kim H, Park S. Characteristics of reported malaria cases, 2020. Public Health Wkly Rep 2021;14:1023-35.

3. Korea Disease Control and Prevention Agency. 2021 Malaria management guidelines. Cheongju: Korea Disease Control and Prevention Agency, 2021.

4. Pan American Health Organization. External quality assurance program for malaria microscopy diagnosis. 
Washington (DC): Pan American Health Organization, 2012.

5. Manser M, Olufsen C, Andrews N, Chiodini PL. Estimating the parasitaemia of Plasmodium falciparum: experience from a national EQA scheme. Malar J 2013;12:428.

6. Tamiru A, Boulanger L, Chang MA, Malone JL, Aidoo M. Field assessment of dried Plasmodium falciparum samples for malaria rapid diagnostic test quality control and proficiency testing in Ethiopia. Malar J 2015;14:11.

7. Mukadi P, Lejon V, Barbe B, Gillet P, Nyembo C, Lukuka A, et al. Performance of microscopy for the diagnosis of malaria and human African trypanosomiasis by diagnostic laboratories in the Democratic Republic of the Congo: results of a nation-wide external quality assessment. PLoS One 2016;11:e0146450.

8. Fei L, Shuang Z, Yi Y, Shan-Shan L, Yan T, Jing-Ru X, et al. Assessment of Malaria microscopy competency at primary health institutions in the Chongqing municipality. Front Med (Lausanne) 2021;8:602442.

9. World Health Organization. Malaria microscopy quality assurance manual, version 2. Geneva: World Heath Organization, 2016.

10. Kim S, Lee K, Park HD, Lee YW, Chun S, Min WK. Schemes and performance evaluation criteria of Korean Association of External Quality Assessment (KEQAS) for improving laboratory testing. Ann Lab Med 2021;41:230-9.

11. Centers for Diseases Control and Prevention. Malaria diagnostic tests. https://www.cdc.gov/malaria/diagnosis_ treatment/diagnostic_tools.html (Accessed August 21, 2021).

12. World Health Organization. Malaria microscopy standard operating procedure-MM-SOP-09: malaria parasite counting. Geneva: World Heath Organization, 2016.

13. Centers for Diseases Control and Prevention. DPDx: laboratory identification of parasites of public health concern: blood specimens: microscopic examination. https://www.cdc.gov/dpdx/diagnosticprocedures/blood/microexam. html (Accessed August 20, 2021).

14. Abdul-Ghani R, Basco LK, Beier JC, Mahdy MA. Inclusion of gametocyte parameters in anti-malarial drug efficacy studies: filling a neglected gap needed for malaria elimination. Malar J 2015;14:413. 